\title{
Research on Intelligent Question Answering System of Network Course for Mu
}

\author{
Huifang Xue $\mathrm{e}^{1, \text { a }}$ \\ ${ }^{1}$ Xi'an International University, Xi'an, Shaanxi, 710077
}

Keywords: Mooc; network course intelligent question and answer system; design

\begin{abstract}
With the development of technology, people is in the form of access to knowledge is constantly changing. The network course intelligent question answering system has become the hotspot and difficulty in the field of natural language processing. It not only integrates the present advanced technology, but also focuses on the realization of the answer to the problem of natural language. On the basis of analyzing the related concepts of $\mathrm{Mu}$, this paper combines the $\mathrm{Mu}$ and the network course intelligent question answering system. On the basis of analyzing the theoretical basis of its design, this paper designs the intelligent Q \& A system of the network course for $\mathrm{Mu}$, hoping to be better Play a system role.
\end{abstract}

\section{Introduction}

Q \& A system is actually a kind of computer program, which has the ability to analyze and deal with natural language, and is an important application in natural language processing technology. The Q \& A system of the online course is a Q \& A system in the field of network teaching. In the network teaching environment, people can be educated at any time without the limitation of time and space [1]. But the network teaching in the provision of convenience at the same time, the same encountered a problem is how to achieve online Q \& A. The traditional teaching model between teachers and students can achieve face to face communication [2], for students in the study of the problems encountered can be resolved in time. However, due to the teaching environment can not be achieved online teaching online, so the design of an advanced, practical application of the network course intelligent question and answer system is very urgent.

Mooc Class. Massive Open Online Course (MOOC, large-scale open online course) is a new type of online learning model, with the traditional network teaching model is very different. $\mathrm{Mu}$ is the biggest feature of the online learning network course learners are large-scale [3], even for the global learners free of charge, with a very obvious spontaneity and sociality.

Mooc since 2007 developed and gradually formed a different platform type to the network, tasks, content-based, different types show different characteristics, can be seen in Table 1.

Table 1 different classification of Mooc

\begin{tabular}{|c|c|c|c|}
\hline & Content-based Mooc & $\begin{array}{l}\text { Based on the network of } \\
\text { Mooc }\end{array}$ & Task - based Mu \\
\hline $\begin{array}{l}\text { Characteristic } \\
\text { s analysis }\end{array}$ & $\begin{array}{lll}\begin{array}{l}\text { Similar } \\
\text { teaching }\end{array} & \text { classroom } \\
\end{array}$ & $\begin{array}{l}\text { Learn knowledge in } \\
\text { communication }\end{array}$ & $\begin{array}{l}\text { Master the skills by } \\
\text { completing the learning task }\end{array}$ \\
\hline $\begin{array}{l}\text { Theoretical } \\
\text { basis }\end{array}$ & Behaviorism & Unicomism & Constructivism \\
\hline $\begin{array}{l}\text { Course } \\
\text { organization }\end{array}$ & $\begin{array}{l}\text { Dynamic Spin of Internal } \\
\text { Spontaneous Organization } \\
\text { and Learning Resources }\end{array}$ & $\begin{array}{l}\text { Dynamic Spin of Internal } \\
\text { Spontaneous Organization } \\
\text { and Learning Resources }\end{array}$ & $\begin{array}{l}\text { Dynamic Spin of Internal } \\
\text { Spontaneous Organization and } \\
\text { Learning Resources }\end{array}$ \\
\hline $\begin{array}{l}\text { Evaluation } \\
\text { method }\end{array}$ & Machine evaluation & N.A & N.A \\
\hline $\begin{array}{l}\text { Typical } \\
\text { project }\end{array}$ & Coursera & PLENK & POT cert \\
\hline
\end{tabular}

\section{The Theoretical Basis of Intelligent Q \& A System Design for Network Course}

Unicom learning theory. Unicom learning theory that learning is not a personal internal activities, 
knowledge is network, Unicom, and learning behavior is to connect the special nodes and information source process. Under this theory, the intelligent question and answer system for the course is to share the ideas of all the learners together to realize the sharing of knowledge [4].

Behaviorist learning theory. The role of behavioral learning theory in the intelligent question and answer system of network course for Mooc can be analyzed from two aspects: design and evaluation of network course. From the design of the network course, it can reflect the principle of small step in the teaching of the program. The content of the course on the platform is based on the knowledge point. From the aspect of the evaluation of the online course, the evaluation method of the intelligent question answering system based on the Mooc course is based on the process evaluation and the formative evaluation. [5] The process evaluation is based on the usual online test and the homework, The formation of evaluation to final examinations or works based.

Constructivist Learning Theory. The theory of constructivist learning is mainly embodied in the three aspects of curriculum implementation, design and evaluation. In the case of course design, for example, most of the course assignments or homework assignments on the Mooc platform require learners to form a learning group to complete the process, which emphasizes that learners construct internal psychological processes in specific contexts of learning and to achieve interaction with the external environment of collaborative learning.

\section{Design and Analysis of Intelligent Question Answering System for Network Course for Mu}

Design Principles. (1) the principle of individuality, the course for the Mu network of intelligent Q \& A system of learners may be from different regions or even the country, the curriculum design must reflect the openness. Learners in the face of Mooc on the platform to learn a high degree of flexibility, learners can learn according to their own free to learn the progress of learning. Therefore, the intelligent question and answer system for the network course is designed to consider the multi-level and multi-angle design [6], not only taking into account the commonality of learners, but also need to consider the learning of the individual.

(2) the principle of situationalism is based on the theory of constructivist learning, the design of the intelligent question answering system for the course of Mooc is best able to be carried out in a certain real situation, which is helpful for learners to deepen their knowledge, knowledge and skills. Master has a good help.

(3) the principle of interactivity, learners can not get timely feedback from learners if they can not achieve interactivity in the intelligent Q \& A system of the course. The interactive nature of the web-based intelligent Q \& A system is mainly reflected in the communication between the platform, the learner and the communication between the instructor and the learner when learning the course content. In the online course intelligent Q \& A system set up online Q \& A, online testing, etc., greatly improve the system interaction [7].

System operation mode selection. The course includes the following modules: login module, knowledge base module, knowledge base intelligent expansion module, keyword module, intelligent answering module, auxiliary answering module, problem management module and system management module. The SQL Server 2008 is a relational database management system (Relational Database Management System), which supports the relational database of the standard query language - structured query language (Structured Query Language-SQL), support for traditional relational database objects and features, but also supports database replication. In order to ensure that the platform for the intelligent course of the intelligent question and answer system platform independent, to the knowledge base table student information table design, for example, see Table 2. 
Table 2 Student Information Sheet Design

\begin{tabular}{|l|l|l|l|}
\hline Field Name & Types & length & Description \\
\hline ID & int & 4 & Serial number \\
\hline username & nvarchar & 50 & Student name \\
\hline psw & nvarchar & 15 & Student password \\
\hline power & nvarchar & 1 & Student authority \\
\hline email & nvarchar & 0 & Student email \\
\hline
\end{tabular}

This study designed the network course intelligent question answering system is to use the network to provide teaching Q \& A service, after the successful connection to the server, the learner can log through the Web browser to the network course intelligent question and answer system, enter and improve the problem content. The server runs the relevant program module to ask questions after receiving the question. On the user layer, the Web browser is the user layer, its role is to provide the user interface to the system display, accept the user's question input or display the results of the return of the server, this layer is not responsible for the interpretation of the meaning. The application layer function is an application request system that handles the front-end client layer as a middle link connecting the user layer and the data service layer, generating the SQL request by the system user to retrieve or update the database, and returning the result to the client. The data service layer provides access and management of various types of data in the database.

System Implementation. After the completion of the system operating environment and the development of tool selection, the beginning of the realization of the data, the entire process contains the database connection and ASP access XML document two aspects. In the user login module, enter the user name and password can enter the system after the main interface, learners can conduct online questions, browse historical issues, online discussions. If you want the fastest answer to a question, you can type it directly in the keyword module and click Retrieve. In this process a practical problem is that the answer is a lot of answers will affect the whole page of the aesthetics, so take the page output, through the use of ADO Recordset object in the Page size, Absolute page, page count three attributes Use to achieve paging. In the auxiliary Q \& A module, if the user in the automatic Q \& A module, the keyword module did not find the required answer, the system will provide online discussion, send mail.

In the intelligent $\mathrm{Q} \& \mathrm{~A}$ module, it is the core of the whole system, which involves the technology, including word segmentation technology, problem similarity calculation technology. In the knowledge base intelligent expansion module, in order to ensure the advanced nature of knowledge, we must take into account the intelligent expansion of the knowledge base, the design of the server through the XMLHTTP technology regularly from the network to crawl the relevant pages, to complete the internal analysis into the knowledge base, Then the experts then review the answers to these questions, modify, etc., to ensure that the knowledge base can be expanded.

Data Security Control. In order to ensure the security of the database, set the appropriate permissions of the database users, to limit each user can only access the necessary database, and filter variables input illegal characters and improperly caused by the insecurity. The contents of the database encrypted and then stored in the database, hoping to protect the system from multiple aspects of the user's personal information security.

\section{Conclusion}

Based on the design and implementation of the intelligent Q \& A system of the network course, this paper summarizes the design principles of the intelligent $\mathrm{Q} \& \mathrm{~A}$ system of the web course for $\mathrm{Mu}$ Cheng, and analyzes the design mode of the network education and the network course Research, and finally build a network course intelligent Q \& A system model, which the main module was designed, and fully take into account the characteristics and needs of Mooc. The short comings of this study are how to achieve voice communication and how to more effectively understand the meaning of the user to express and achieve a more accurate answer to extract. 


\section{Acknowledgements}

This work is supported by the special research project of the Education Department of Shaanxi Province of China (No. 15JK2133);

\section{References}

[1] Wang Lihua. The new development of "Mooc" in the United States and its enlightenment to China - Based on the interpretation of the series of investigation and evaluation of Sloan Union [J] .Journal of Educational Management, 2014,31 (05): 34-40 + 72.

[2] Xiong Haifan. Application of Mooc Teaching in the Innovation of Special Education in the Perspective of "Epiphany": Mode, Course and Organization [J]. Computer Education Research, 2014, 17 (12): 16-22.

[3] Yang Manfu, Jiao Jianli. Big teaching, big data, big change - edX first "Mooc" research report analysis and enlightenment [J] .Investment Education Research, 2014, 19 (06): 34-37 +50

[4] Xiao Zhanjun, Xin Baozhong. The advent of college survival crisis or the beginning of the popularization of higher education - University of Mooc research and practice of the shift and future trends [J]. China Audio-Visual Education, 2015, 27 (03): 35-38.

[5] Li Yashi. Mooc research status review: hot spots and trends - based on the 2009-2014 CNKI published keywords of the co-word visualization analysis [J] .Investment Education Research, 2015,19 (07): 55-60.

[6] Zhang Diane. Foreign language oral design and practice study - "Mooc English 900 cases" as an example [J]. Foreign language circles, 2015, 11 (04): 90-96.

[7] Li Yan, Zhang Muhua. College students Mooc and flip classroom experience empirical study based on 231 online learning log analysis [J]. Modern distance education research, 2015, 27 (05): $73-84+93$. 